\title{
RESEARCH
}

Open Access

\section{APOC3 genetic variation, serum triglycerides, and risk of coronary artery disease in Asian Indians, Europeans, and other ethnic groups}

Shiwali Goyal ${ }^{1}$, Yosuke Tanigawa², Weihua Zhang ${ }^{3,4}$, Jin-Fang Chai ${ }^{5}$, Marcio Almeida ${ }^{6}$, Xueling Sim ${ }^{5}$, Megan Lerner ${ }^{7}$, Juliane Chainakul ${ }^{8}$, Jonathan Garcia Ramiu ${ }^{8}$, Chanel Seraphin ${ }^{8}$, Blair Apple ${ }^{8}$, April Vaughan $^{8}$, James Muniu', Juan Peralta ${ }^{6}$, Donna M. Lehman ${ }^{9}$, Sarju Ralhan ${ }^{10}$, Gurpreet S. Wander ${ }^{10}$, Jai Rup Singh ${ }^{11}$, Narinder K. Mehra ${ }^{12}$, Evgeny Sidorov ${ }^{8}$, Marvin D. Peyton ${ }^{7}$, Piers R. Blackett ${ }^{13}$, Joanne E. Curran ${ }^{6}$, E. Shyong Tai ${ }^{5,14,16}$, Rob van Dam ${ }^{4,14,15}$, Ching-Yu Cheng ${ }^{16,17,18}$, Ravindranath Duggirala ${ }^{6}$, John Blangero ${ }^{6}$, John C. Chambers ${ }^{3,4,19,20,21}$, Charumathi Sabanayagam ${ }^{16,17}$, Jaspal S. Kooner ${ }^{4,20,21,22}$, Manuel A. Rivas ${ }^{2}$, Christopher E. Aston ${ }^{1}$ and Dharambir K. Sanghera ${ }^{1,23,24,25,26^{*}}$

\section{Abstract}

Background: Hypertriglyceridemia has emerged as a critical coronary artery disease (CAD) risk factor. Rare loss-offunction (LOF) variants in apolipoprotein C-III have been reported to reduce triglycerides (TG) and are cardioprotective in American Indians and Europeans. However, there is a lack of data in other Europeans and nonEuropeans. Also, whether genetically increased plasma TG due to ApoC-III is causally associated with increased CAD risk is still unclear and inconsistent. The objectives of this study were to verify the cardioprotective role of earlier reported six LoF variants of APOC3 in South Asians and other multi-ethnic cohorts and to evaluate the causal association of $\mathrm{TG}$ raising common variants for increasing CAD risk.

Methods: We performed gene-centric and Mendelian randomization analyses and evaluated the role of genetic variation encompassing APOC3 for affecting circulating TG and the risk for developing CAD.

\footnotetext{
* Correspondence: Dharambir-sanghera@ouhsc.edu

'Department of Pediatrics, College of Medicine, University of Oklahoma

Health Sciences Center, 940 Stanton L. Young Blvd., Rm 317 BMSB, Oklahoma City, OK 73104, USA

${ }^{23}$ Department of Pharmaceutical Sciences, University of Oklahoma Health Sciences Center, Oklahoma City, OK, USA

Full list of author information is available at the end of the article
}

(C) The Author(s). 2021 Open Access This article is licensed under a Creative Commons Attribution 4.0 International License, which permits use, sharing, adaptation, distribution and reproduction in any medium or format, as long as you give appropriate credit to the original author(s) and the source, provide a link to the Creative Commons licence, and indicate if changes were made. The images or other third party material in this article are included in the article's Creative Commons licence, unless indicated otherwise in a credit line to the material. If material is not included in the article's Creative Commons licence and your intended use is not permitted by statutory regulation or exceeds the permitted use, you will need to obtain permission directly from the copyright holder. To view a copy of this licence, visit http://creativecommons.org/licenses/by/4.0/. The Creative Commons Public Domain Dedication waiver (http://creativecommons.org/publicdomain/zero/1.0/) applies to the data made available in this article, unless otherwise stated in a credit line to the data. 
Results: One rare LoF variant (rs138326449) with a 37\% reduction in TG was associated with lowered risk for CAD in Europeans $(p=0.007)$, but we could not confirm this association in Asian Indians ( $p=0.641)$. Our data could not validate the cardioprotective role of other five LoF variants analysed. A common variant rs5128 in the APOC3 was strongly associated with elevated TG levels showing a $p$-value $2.8 \times 10^{-424}$. Measures of plasma ApoC-III in a small subset of Sikhs revealed a 37\% increase in ApoC-III concentrations among homozygous mutant carriers than the wild-type carriers of rs5128. A genetically instrumented per 1SD increment of plasma TG level of $15 \mathrm{mg} / \mathrm{dL}$ would cause a mild increase (3\%) in the risk for CAD $(p=0.042)$.

Conclusions: Our results highlight the challenges of inclusion of rare variant information in clinical risk assessment and the generalizability of implementation of ApoC-III inhibition for treating atherosclerotic disease. More studies would be needed to confirm whether genetically raised TG and ApoC-III concentrations would increase CAD risk.

Keywords: ApoC-III, Rare and common variants, Mendelian randomization, Triglyceride, Coronary artery disease risk, Asian Indians

\section{Highlights}

- There is a strong influence of genetic factors for controlling circulating triglycerides (TG). However, the causal association between hypertriglyceridemia and the development of coronary artery disease $(\mathrm{CAD})$ is unclear. Earlier published studies have primarily examined individuals from European populations. For the first time, in this study, we have included data from Asian Indians with Europeans and other ethnic groups to identify the causal association of genetically raised TG due to ApoC-III with the risk for CAD.

- We also evaluated the role of six earlier reported loss-of-function rare variants in $A P O C 3$ for protecting CAD. Only one variant IVS2 + 1G-A (rs138326449), showed $\sim 37 \%$ reduction in TG and had a significantly lower risk for CAD $(0.6495 \% \mathrm{CI}$ $0.47-0.88 ; p=0.007$ ), but its phenotypic effects could not be confirmed in Asian Indians.

- A common variant rs5128 in the APOC3 was strongly associated with elevated TG across all cohorts showing a meta-analysis $p$-value of $2.80 \times$ $10^{-424}$.

- We have used genetic instrumental variable methods to obtain estimates of the causal association between circulating TG levels and CAD for determining the direction of causality by performing a Mendelian randomization study. Genetically instrumented per 1SD increment of plasma TG level of $15 \mathrm{mg} / \mathrm{dL}$ would cause a mild increase of $3 \%$ in the risk for CAD $(p=0.042)$.

\section{Introduction}

Hypertriglyceridemia (HTG) is a common disorder of blood lipids associated with elevated blood triglyceride (TG) concentration. Except for the very rare monogenic form of HTG [1], the common form of HTG is also a heritable genetic condition and a risk factor for coronary artery disease (CAD). Genetic variation in several genes involved in TG hydrolysis, obesity, and metabolic syndrome, are implicated in influencing polygenic HTG, which makes the clinical management of HTG extremely challenging [2]. HTG can also develop from secondary causes such as poorly managed type 1 or type 2 diabetes, hypothyroidism, renal insufficiency, and as side effects of certain medications (estrogen, beta-blockers, diuretics, glucocorticoids, antidepressants, and antipsychotics) [3, 4]. Lipoprotein lipase (LPL) is an important regulator of lipid metabolism and plays a key role in the hydrolysis of TG-rich very-low-density lipoproteins (VLDL), intermediate-density lipoproteins, and chylomicron remnants [5]. Apolipoprotein C-III (ApoC-III) is an inhibitor of LPL and obstructs the hepatic uptake of TG-rich lipoproteins and lipoprotein remnants. A blood TG level< $150 \mathrm{mg} / \mathrm{dL}$ is considered normal. An increase of TG > $150 \mathrm{mg} / \mathrm{dL}(150-199 \mathrm{mg} / \mathrm{dL})$ is classified as moderate HTG, and > $200 \mathrm{mg} / \mathrm{dL}$ ( 200 or $250 \mathrm{mg} / \mathrm{dL}$ ) is considered high HTG, and above $500 \mathrm{mg} / \mathrm{dL}$ is defined as severely elevated HTG [6-8]. Elevated blood ApoC-III is correlated with increased TG and increased risk for myocardial infarction and CAD [9]. Average blood ApoC-III concentration of $\sim 10 \mathrm{mg} / \mathrm{dL}$ or lower correlates with normal TG and $>20 \mathrm{mg} / \mathrm{dL}$ with HTG [10]. However, very few investigators have measured ApoC-III levels in human studies.

The APOC3 gene that encodes ApoC-III is located within the APOA5-APOA4-APOC3-APOA1 gene cluster in the chromosomal region 11q23.3. Common genetic variants-specifically in the promoter or $5^{\prime}(\mathrm{T}-455 \mathrm{C}$, C$482 \mathrm{~T}$ ) and 3' UTR (Sst-1 or rs5128) regions, have consistently been shown to be robustly associated with blood lipid levels in candidate gene- and genome-wide association studies (GWAS) [11, 12]. Meta-analyses of GWAS in multi-ethnic populations have shown strong association signals between the APOA5-APOA4-APOC3- 
APOA1 gene cluster and circulating TG levels [13, 14]. However, whether the genetically enhanced TG (owing to the $A P O C 3$ common variants) increases CAD risk remains inconclusive across many studies.

Resequencing studies of the APOC3 gene have identified rare null variants with strong phenotypic effects associated with lower TG levels in recent studies $[15,16]$. A rare missense variant (A43T; rs147210663; earlier notation A23T) in the APOC3 found in Yucatan Indians was linked with ApoC-III deficiency with reduced blood TG concentration [17]. Another rare loss-of-function (LoF) variant in APOC3 (initially found in an Amish population) (R19X; rs76353203) was associated with reduced TG levels. The heterozygous minor allele carriers had a 50\% reduced ApoC-III concentration compared to non-carriers [15]. A sequencing study on the Danish population from Europe and the results of the Exome Sequencing Project of the National Heart, Lung, and Blood Institute on epidemiological cohorts (predominantly of US white) also confirmed earlier known rare variants to be associated with reduced TG and, hence, protective against CAD $[16,18]$. However, there is a paucity of data on whether these or other rare and common variants in the APOC3 would show the same phenotypic effects that would be cardio-protective in other European and nonEuropean populations, particularly the populations of Asian Indians. People of the Indian diaspora contribute the highest number of CAD deaths worldwide and in their countries of origin [19]. Epidemiological studies suggest that people of Asian Indian descent exhibit an increased predisposition for earlier and acute myocardial infarction and atherosclerotic cardiovascular disease that is not explained by traditional risk factors [20]. Therefore, the purpose of this study was: 1) to perform gene-centric analysis of the APOC3 region to identify common and rare variants associated with TG;2) to verify the cardioprotective role of earlier reported LoF/reduced-function variants of the $A P O C 3$; and 3) to analyze whether genetically raised TG due to $A P O C 3$ variation would increase the development of CAD, in Asian Indian and other multi-ethnic cohorts comprising 396,644 individuals.

\section{Methods}

\section{Study cohorts}

Our study investigated 396,644 individuals comprised of 4659 Asian Indians from India and the US (AIDHS/ SDS) [21-23]; 11,339 Asian Indians from London, UK (LOLIPOP) [24]; 2713 Asian Indians (MEC_Indian, and SINDI) from Singapore [25], 7885 Asian Indians from UK BIOBANK (UKBB) [26], and 2999 Chinese (MEC_ Chinese and DC_SP2) from Singapore [27]. Additionally, we included 2153 Europeans from London, UK (LOLIPOP) [24]; 362,043 Europeans from UKBB [28]; 2341 Mexican Americans from San Antonio (SAMAFS) [29], and 512 multi-ethnic individuals from Oklahoma (MISS_OLIVER) [30]. Details of clinical and demographic characteristics of all cohorts are described in Table 1. Diagnostic criteria for CAD cases and nonCAD controls in participating study cohorts are summarized in Supplementary Table 1.

Table 1 Clinical attributes of study cohorts

\begin{tabular}{|c|c|c|c|c|c|c|c|c|c|}
\hline Cohort & $\begin{array}{l}\text { AIDHS/SDS } \\
N=4659\end{array}$ & $\begin{array}{l}\text { LOLIPOP }_{-} \\
\mathrm{Al} \\
N= \\
11,339\end{array}$ & $\begin{array}{l}\text { LOLIPOP } \\
\text { EU } \\
N=2153\end{array}$ & $\begin{array}{l}\text { SINGAPORE } \\
\text { AI } \\
N=2713\end{array}$ & $\begin{array}{l}\text { SINGAPORE_- } \\
\text { CHS } \\
N=2999\end{array}$ & $\begin{array}{l}\text { SAMAFS } \\
\text { (MEXICANS) } \\
N=2341\end{array}$ & $\begin{array}{l}\text { MISS_OLIVER } \\
\text { (MULTIETHNIC) } \\
N=512\end{array}$ & $\begin{array}{l}\text { UKBB_AI } \\
N=7885\end{array}$ & $\begin{array}{l}\text { UKBB_EU } \\
N= \\
362,043\end{array}$ \\
\hline Ancestry & $\mathrm{Al}$ & $\mathrm{Al}$ & EU & $\mathrm{Al}$ & $\mathrm{CHS}$ & MEX & MULTI-ETHNIC & $\mathrm{Al}$ & $\mathrm{EU}$ \\
\hline $\mathrm{N}$ & 4659 & 11,339 & 2153 & 2713 & 2999 & 2341 & 512 & 7885 & 362,043 \\
\hline Female (\%) & 44 & 19 & 15 & 51 & 49 & 58 & 52 & 45 & 54 \\
\hline CAD (\%) & 17 & 26 & 27 & NA & NA & 10 & 27 & 7 & 4 \\
\hline Age (yrs) & $\begin{array}{l}52.14 \pm \\
13.21\end{array}$ & $\begin{array}{l}52.13 \pm \\
9.67\end{array}$ & $\begin{array}{l}56.99 \pm \\
8.96\end{array}$ & $55.08 \pm 9.24$ & $54.49 \pm 8.59$ & $53.78 \pm 15.12$ & $53.78 \pm 16.47$ & $66.68 \pm 8.3$ & $\begin{array}{l}70.29 \pm \\
7.39\end{array}$ \\
\hline $\begin{array}{l}\text { BMI }(\mathrm{kg} / \\
\left.\mathrm{m}^{2}\right)\end{array}$ & $26.78 \pm 4.84$ & $\begin{array}{l}27.91 \pm \\
4.34\end{array}$ & $\begin{array}{l}29.62 \pm \\
5.18\end{array}$ & $26.66 \pm 5.06$ & $24.32 \pm 3.81$ & $32.31 \pm 7.7$ & $29.26 \pm 6.52$ & $26.91 \pm 7.42$ & $\begin{array}{l}29.41 \pm \\
5.61\end{array}$ \\
\hline TG (mg/dL) & $\begin{array}{l}169.94 \pm \\
107.59\end{array}$ & $\begin{array}{l}159.24 \pm \\
100.9\end{array}$ & $\begin{array}{l}176.79 \pm \\
131.9\end{array}$ & $\begin{array}{l}154.53 \pm \\
94.58\end{array}$ & $130.68 \pm 79.32$ & $165.33 \pm 105.36$ & $147.92 \pm 97.23$ & $\begin{array}{l}180.73 \pm \\
104.43\end{array}$ & $\begin{array}{l}175.41 \pm \\
99.51\end{array}$ \\
\hline $\begin{array}{l}\text { HDL-C (mg/ } \\
\mathrm{dL})\end{array}$ & $\begin{array}{l}40.81 \pm \\
14.47\end{array}$ & $\begin{array}{l}48.43 \pm \\
12.04\end{array}$ & $\begin{array}{l}48.34 \pm \\
10.14\end{array}$ & $41.93 \pm 12.09$ & $54.10 \pm 13.87$ & $47.98 \pm 13.98$ & $41.46 \pm 12.98$ & $46 \pm 11.52$ & $\begin{array}{l}51.01 \pm \\
13.35\end{array}$ \\
\hline $\begin{array}{l}\text { LDL-C (mg/ } \\
\mathrm{dL})\end{array}$ & $\begin{array}{l}110.40 \pm \\
38.42\end{array}$ & $\begin{array}{l}122.33 \pm \\
34.97\end{array}$ & $\begin{array}{l}117.43 \pm \\
35.87\end{array}$ & $\begin{array}{l}125.99 \pm \\
34.74\end{array}$ & $117.27 \pm 30.86$ & $113.3 \pm 32.36$ & $109.67 \pm 39.96$ & $\begin{array}{l}117.34 \pm \\
30.93\end{array}$ & $\begin{array}{l}122.82 \pm \\
32.94\end{array}$ \\
\hline
\end{tabular}

Values are displayed in mean \pm SD; Al Asian Indians, EU Europeans, CHS Chinese, MEX Mexicans, CAD Coronary Artery Disease, BMI Body-Mass Index, TG Triglycerides, HDL-C High-Density Lipoprotein-Cholesterol, LDL-C Low-Density Lipoprotein-Cholesterol, AIDHS/SDS Asian Indian Diabetic Heart Study/Sikh Diabetes Study, LOLIPOP The London Life Sciences Prospective Population Study, SAMAFS San Antonio Mexican American Family Studies, UKBB UK BIOBANK, MISS-OLIVER Metabolome in Ischemic Stroke Study and Oklahoma Multiethnic CardioVascular Health Disparity Study 


\section{Genotyping and sequencing}

Details of genome-wide genotype and sequencing information are described in the online Supplementary Section and Supplementary Table 2.

\section{Serum/plasma ApoC-III measurements using ELISA}

Circulating concentrations of ApoC-III were quantified using frozen serum aliquots by enzyme-linked immunosorbent assay (ELISA) kits from Thermofisher Scientific (Waltham, MA, USA) following the manufacturer's instructions. Briefly, the Thermofisher's Human ApoC-III ELISA Kit was based on solid-phase sandwich ELISA technology with a target-specific antibody pre-coated onto 96-well plates, and test samples were added to the wells in duplicates. A biotinylated detection polyclonal antibody was added subsequently and then followed by washing with $1 \mathrm{x}$ PBS buffer. Avidin-biotin-peroxidase complex was added, and unbound conjugates were washed away with $1 \mathrm{x}$ PBS buffer. Horseradish peroxidase (HRP) substrate 3,3',5,5' -tetramethylbenzidine (TMB) was used to visualize HRP enzymatic reaction. TMB was catalyzed by HRP to produce a blue color product that changed into yellow after adding an acidic stop solution. The density of yellow color is proportional to the Human ApoC-III concentration of sample captured in the plate, and the optical density (OD) absorbance was measured at $450 \mathrm{~nm}$ by GENEMATE microplate reader. Samples were blinded for ApoC-III measurements, and each specimen was run in duplicate. A standard curve was generated and used to determine the ApoC-III level in the tested serum samples. The ApoC-III measures were performed in a selected subset of 38 Sikh individuals, half with wild-type (CC), half with mutant genotype (GG).

\section{Statistical analysis \\ Genetic association analysis}

Each study site provided summary statistics of the association for all available rare variants (with a minor allele frequency $(\mathrm{MAF})<1 \%$ ) and common variants (MAF $\geq$ $5 \%$ ) within the region encompassing the open reading frame of the APOC3. Statistical evaluations of genetic effects of common and rare variants on lipid panel and other metabolic traits and CAD were performed using multivariable logistic and linear regression models using covariates such as age, gender, BMI, and diabetes. Principal components (PC) were included in the models to adjust for the population structure as described previously $[21,22]$. As the existing HapMap and 1000 Genomes data do not include Sikhs, the 5 principal components used for this correction were estimated using our Sikh population samples as described earlier [21]. We genotyped the discovery and the replication datasets of AIDHS/SDS set using Human 660W Quad
BeadChip and Illumina's Global Screening Array (Illumina, Inc., San Diego, CA) as described previously [23]. We also performed pairwise identity-by-state (IBS) clustering in PLINK across all individuals to assess population substructure due to cryptic relatedness and to remove outliers. Samples with $<93 \%$ call rate, SNPs with $<95 \%$ call rate, SNPs with deviation from HardyWeinberg Equilibrium (HWE; $p<10^{-6}$ ), and individuals with gender discrepancies were excluded from the analysis. To increase genome coverage, imputation was performed using Minimac4 [31] (https://imputationserver. sph.umich.edu/) with 1000G Phase 3 v5 multi-ethnic reference panel in NCBI Build 37 (hg19) coordinates as described [22, 23]. Quality control for the imputed SNPs included removal of variants with an imputation certainty info score $\left(\mathrm{R}^{2}\right)<0.8$ and SNPs significantly deviated from HWE in controls $\left(p<1 \times 10^{-6}\right)$. From a total of 46,511,137 variants, 9,400,020 variants with MAF > $1 \%$ were available after the quality control. For this study, we performed a locus-wide association of chromosome 11 encompassing $A P O C 3$ and its flanking regions (116698024-116,710,387) for common variant association analysis. We selected all independent signals $\left(p \leq 10^{-3}\right)$ from Sikh discovery $(n=820)$ with MAF $\geq 5 \%$ for replication and look-up in GWAS in replication cohorts of Sikhs (AIDHS/SDS) $(n=3839)$ and other Asian Indians (from Asian Indian component of the LOLIPOP, Singapore, and South Asian component of the UKBB), Europeans (LOLIPOP, UKBB), and Others (including Singapore Chinese [MEC_CHS], Mexican American [SAMAFS], and African American, Hispanic and mixed ethnicity [MISS-OLIVER]) (Table 1). General mixed linear models were used to test the impact of genetic variants on transformed continuous traits using the variance-component test adjusted for the random-effects of relatedness to account for family structure and fixed effects of age, gender, BMI, and diabetes status and PCs assuming an additive genetic model using SVS version 8.8.3 (Golden Helix, Bozeman, MT, USA) [23]. Continuous traits with skewed sampling distributions (e.g., TG) were log-transformed before statistical analysis. However, for illustrative purposes, values were re-transformed into the original measurement scale. Meta-analysis was performed on selected SNPs showing significant association in most of the study cohorts. To combine common SNP association results from all cohorts, both fixed and random effect inverse variance metanalysis implemented in METAL [32] was employed. Two-tailed $p$-values lower than $5 \times 10^{-8}$ were considered genome-wide significant. The LocusZoom standalone tool was used to generate a regional association plot for the APOC3 locus [33]. The Forest Plot Viewer (http://ntp.niehs.nih.gov/ntp/ohat/ forestplot/) and PRISM (https://www.graphpad.com/ scientific-software/prism/) were used to generate forest 
plots. For determining the association of the five known rare variants for CAD, a value of 0.5 is added to all the cells where zeros caused problems in the computation of odds ratios as described [34].

\section{Mendelian randomization (MR) studies}

In general, elevated plasma TG is known to increase the risk for $\mathrm{CAD}$ in epidemiological and prospective studies; however, whether the genetically increased TG is causally related to the development of CAD is still unknown. The MR approach uses the genetic variation as an instrumental variable (IV) to define the causal association between a risk factor or exposure (e.g., TG) with the disease (e.g., CAD) [35, 36]. The basic principle of the MR methodology is based on the assumptions that the IV (APOC3 genotype) associated with the phenotype (TG), is independent of known and unknown confounders, and it can only influence the outcome (i.e., CAD) through the exposure (TG). To ensure that the MR assumptions were not violated, we chose the APOC3 variant with the strongest independent association with the exposure (i.e., TG) across all cohorts and pruned the SNPs in linkage disequilibrium (LD). Further, the SNP used as a Mendelian instrument was not associated with the outcome via exposure to other confounding factors (BMI, age, gender, and diabetes). For assessing the causal association of exposure with the outcome, we used a one-sample MR using the inverse-variance method.

\section{Results}

\section{Genetic associations of common variants with TG and} CAD

A gene-centric association analysis was performed on all directly genotyped and high-quality imputed SNPs within the $A P O C 3$ region with MAF $\geq 5 \%$ to identify gene variants associated with TG concentrations using multiple linear regression controlling for age, gender, BMI, diabetes, and PCs. Of all common variants surveyed from the open reading frame of the $A P O C 3$, two variants [rs5128 (3' UTR) (Fig. 1) and rs734104 (intronic)] showed a strong association with increased plasma TG in Sikhs (AIDHS). These two variants were
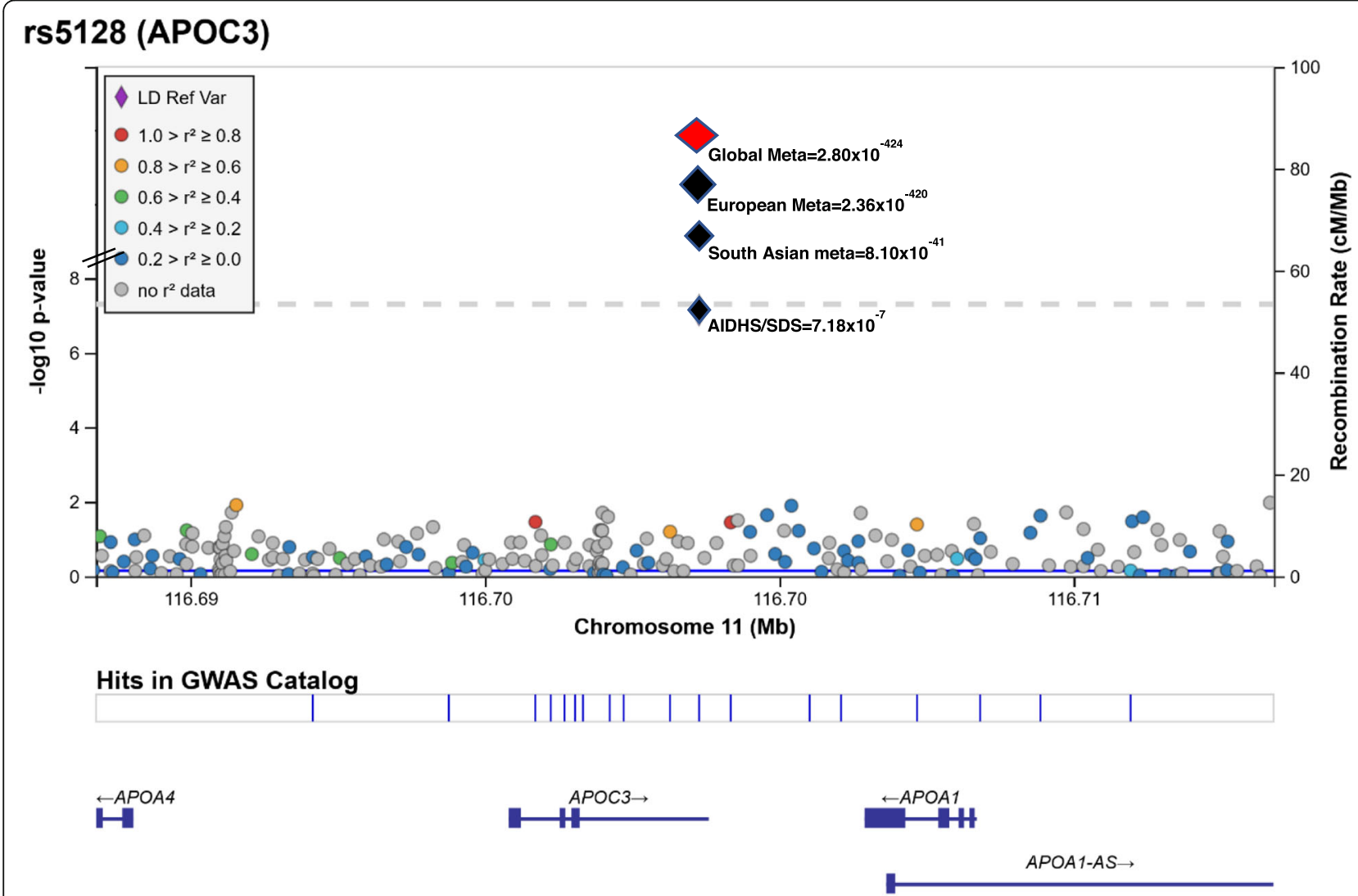

Fig. 1 Regional association plot for the APOC3 common variant rs5128 showing association with plasma triglyceride levels. SNPs from the APOC3 region are plotted by position on the $x$-axis versus association with triglyceride levels $(-\log 10 P)$ on the $y$-axis. The black diamond signifies $p$ values of the studied SNP (rs5128) in Sikhs and in the combined analysis using replication studies. Global meta-analysis results are depicted by a red diamond at the top of the plot. The SNPs surrounding the most significant SNP are color-coded to reflect their LD with this SNP. We present linkage disequilibrium (LD) using the GIH panel (Gujarati Indians in Houston), the closest HapMap population to the Sikhs. At the bottom of the plot, the locations of known genes in the region are shown 


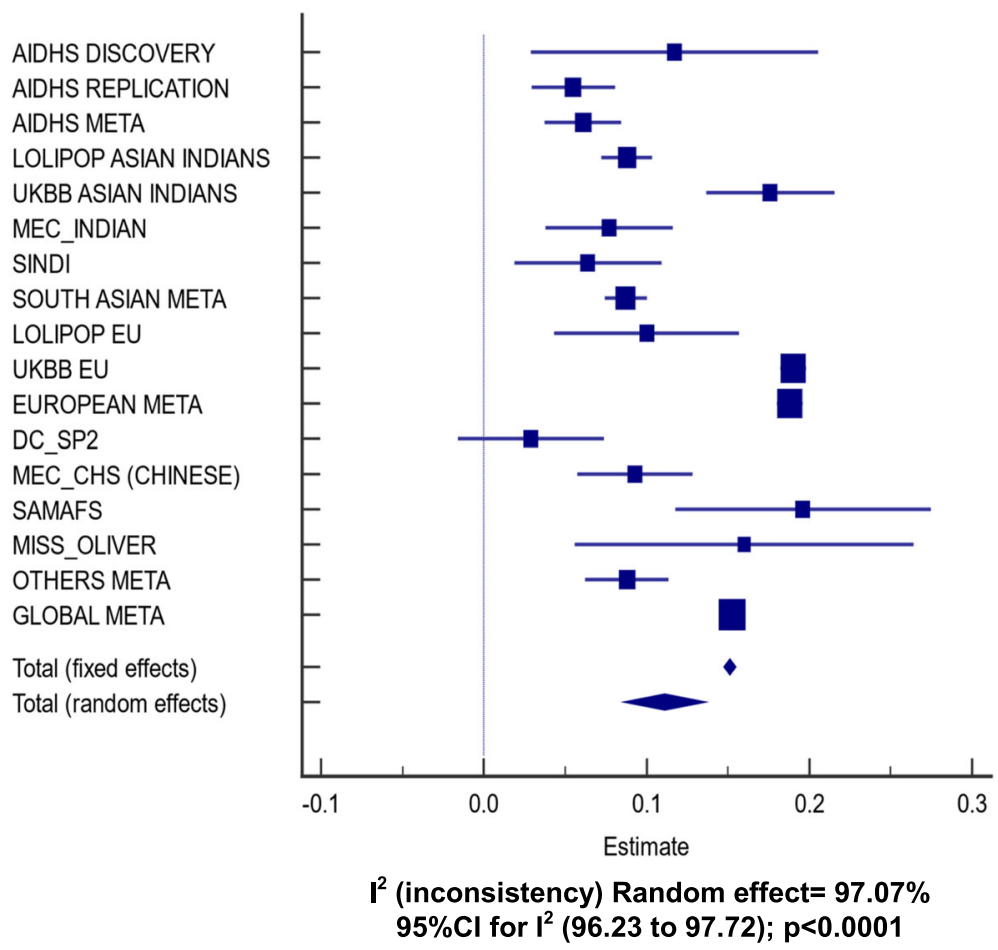

Fig. 2 Random-effect metanalysis showing allelic effects of the APOC3 common variant rs5128 with plasma TG levels among 396,644 participants from different ethnic cohorts. Analysis was adjusted for age, gender, BMl, diabetes, and 5 principal components using linear regression

in LD with each other $\left(r^{2}=0.78\right)$, therefore, we only used one variant (rs5128) as a genetic instrument (IV) for MR studies. The estimates $(\beta \pm \mathrm{SE})$ for rs5128 for effecting TG levels was $0.06 \pm 0.01 ; p=7.18 \times 10^{-7}$ after adjusting for the effects of age, gender, BMI, diabetes, and PCs. (Fig. 2, Supplementary Table 3). Similarly, rs5128 showed a robust replication with significantly raised TG $\left(0.09 \pm 0.01 ; p=8.10 \times 10^{-41}\right)$ in other independent Asian Indian cohorts (LOLIPOP, UKBB_AI, MEC_INDIAN, and SINDI). Apart from South Asians, the highly significant association of this variant was also observed in Europeans (LOLIPOP, and UKBB) $(0.19 \pm$ $0.004 ; p=2.36 \times 10^{-420}$ ) and others (MEC_CHS, DC_ SP2, SAMAFS, MISS_OLIVER) $(0.09 \pm 0.01 ; p=1.15 \times$ $\left.10^{-11}\right)$, adjusting for the effects of age, gender, BMI, diabetes, and PCs. A global meta-analysis across all cohorts showed strong allelic results of rs5128 for increasing plasma TG $\left(0.15 \pm 0.004, p=2.80 \times 10^{-424}\right.$ (Fig. 2; Supplementary Table 3). No association of this variant was observed with T2D, LDL-cholesterol, and total cholesterol (data not shown). A per SD increase of TG of 15 $\mathrm{mg} / \mathrm{dL} \pm 0.004 \mathrm{mg} / \mathrm{dL}\left(p=2.80 \times 10^{-424}\right)$ for $\mathrm{rs} 5128$ is predicted to increase CAD risk by $3 \% 95 \%$ CI [0-5\%]; $p=0.042$. (Fig. 3; Supplementary Table 3).

We also explored if genetically raised TG will correlate with increased ApoC-III concentration. For this, we measure serum ApoC-III levels in a small subset of 38
Sikh individuals, half with homozygous wild type (CC) and half with mutant (GG) alleles of rs5128. The correlation between serum TG and serum ApoC-III levels was significantly positive $(r=0.54, p=0.0004)$ (Fig. 4A) which is very similar to an earlier published study $(r=$ $0.59 ; p<1 \times 10^{-4}$ ) [37]. While there was a $76 \%$ increase in TG level among the mutant homozygous carriers than the wild type carriers (Fig. 4B), the ApoC-III levels increased $37 \%$ among the mutant homozygous carriers compared to the wild type carriers (Fig. 4C).

\section{Association of previously known $A P O C 3$ rare variants with TG and CAD}

We evaluated the role of previously reported rare variants for their association with TG and CAD in our cohort. We observed a total of 56 carriers of null variant rs76353203 (R19X): one carrier of Sikh ancestry (India), two Asian Indians, and 53 European carriers from UKBB (Table 2). Five (9\%) of the 53 European carriers of this variant from UK BIOBANK were affected with CAD (Fig. 5).

All other known variants detected in AIDHS/SDS and other cohorts were not associated with low TG levels as seen in white populations in published studies. For instance, 12 heterozygous carriers (IVS3 + 1GT; rs140621530) of Punjabi Sikh ancestry (AIDHS/SDS) had high TG (ranging from 133 to $469 \mathrm{mg} / \mathrm{dL}$ ); three 


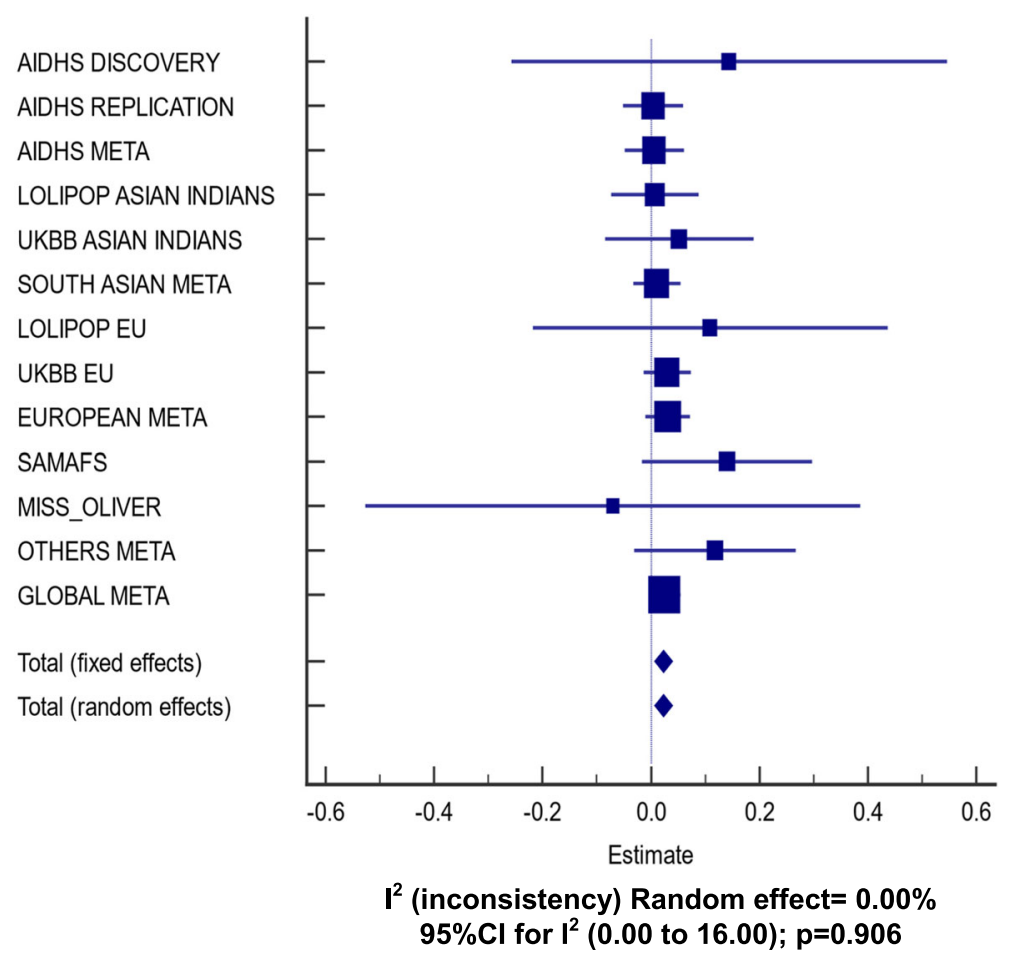

Fig. 3 Random-effect metanalysis showing allelic effects of the APOC3 common variant rs5128 with CAD among 390,932 participants from different ethnic cohorts. Analysis was adjusted for age, gender, BMI, diabetes, and 5 principal components using logistic regression

heterozygous US white carriers from MISS_OLIVER also had high TG levels (average $141 \mathrm{mg} / \mathrm{dL}$ ). In contrast, one African American carrier from MISS_OLIVER had low TG $(78 \mathrm{mg} / \mathrm{dL})$, but this individual was a CAD patient. In the UKBB European cohort, eight carriers were observed with a mean TG level of $92.2 \mathrm{mg} / \mathrm{dL}$. A single carrier of a known rare variant D65N (rs149707394) observed in UKBB (European) had a plasma TG of 377.7 $\mathrm{mg} / \mathrm{dL}$ (Fig. 5).

Our data detected 18 carriers of A43T (rs147210663) in AIDHS/SDS and only two of 18 showed reduced TG $(57 \pm 31 \mathrm{mg} / \mathrm{dL}$; range $35-79 \mathrm{mg} / \mathrm{dL})$ while the remaining 16 individuals had elevated TG (mean $267 \pm$ $101 \mathrm{mg} / \mathrm{dL}$; range 142 to $464 \mathrm{mg} / \mathrm{dL}$ ). One of the two carriers of A43T with very low TG $(35 \mathrm{mg} / \mathrm{dL})$ also had low HDL-C (22 mg/dL). Four carriers of A43T were also observed in UKBB (Asian Indian) with a mean TG level of $111.3 \mathrm{mg} / \mathrm{dL}$. Furthermore, 300 carriers of A43T of UKBB (European) had a mean TG of $117.7 \mathrm{mg} / \mathrm{dL}$, and 11/300 (4\%) had CAD. A single Mexican American carrier from SAMAFS had a low TG level of $46 \mathrm{mg} / \mathrm{dL}$ and an African American from MISS_OLIVER had low TG (69 mg/dL) (Fig. 5).

We performed a combined association analysis of five known rare variants (found in most of the cohorts). Even though the plasma mean TG levels were significantly lower among the variant allele carriers vs. the wild type carriers, none of these variants exhibited any significant protection against CAD except for the rs138326449 (IVS2 + 1G-A). As shown in Table 2, the splice variant rs138326449 was associated with a significantly reduced risk for CAD (OR 0.64 95\%CI 0.47-0.88; $p=0.007$ ) with $\sim 37 \%$ reduction in TG in the combined sample. However, the cardioprotective effect of this variant was not significant in Asian Indians when data was analyzed separately $(\mathrm{OR}=0.5095 \% \mathrm{CI} 0.03-9.26 ; p=0.641)$ (Table 3$)$. Similarly, no other variant revealed any significant protective association against CAD despite showing a reduced concentration of TG in Europeans or other populations used in our study (Tables 2 and 3).

\section{Discussion}

The role of ApoC-III in lipid metabolism has been well-documented in human and animal studies. However, the molecular mechanism of the action of ApoCIII in lipid metabolism and CAD is still unclear. The discovery of LoF or reduced function variants in $A P O C 3$ and other lipid genes has started shedding light on their putative molecular role in lipid metabolisms. Because these LoF/reduced function variants were shown to be cardioprotective in recent studies, there has been a consensus to therapeutically inhibit ApoCIII for treating dyslipidemia and prevent CAD susceptibility using antisense oligos [38]. However, as most of the large-size studies have been heavily focused on 

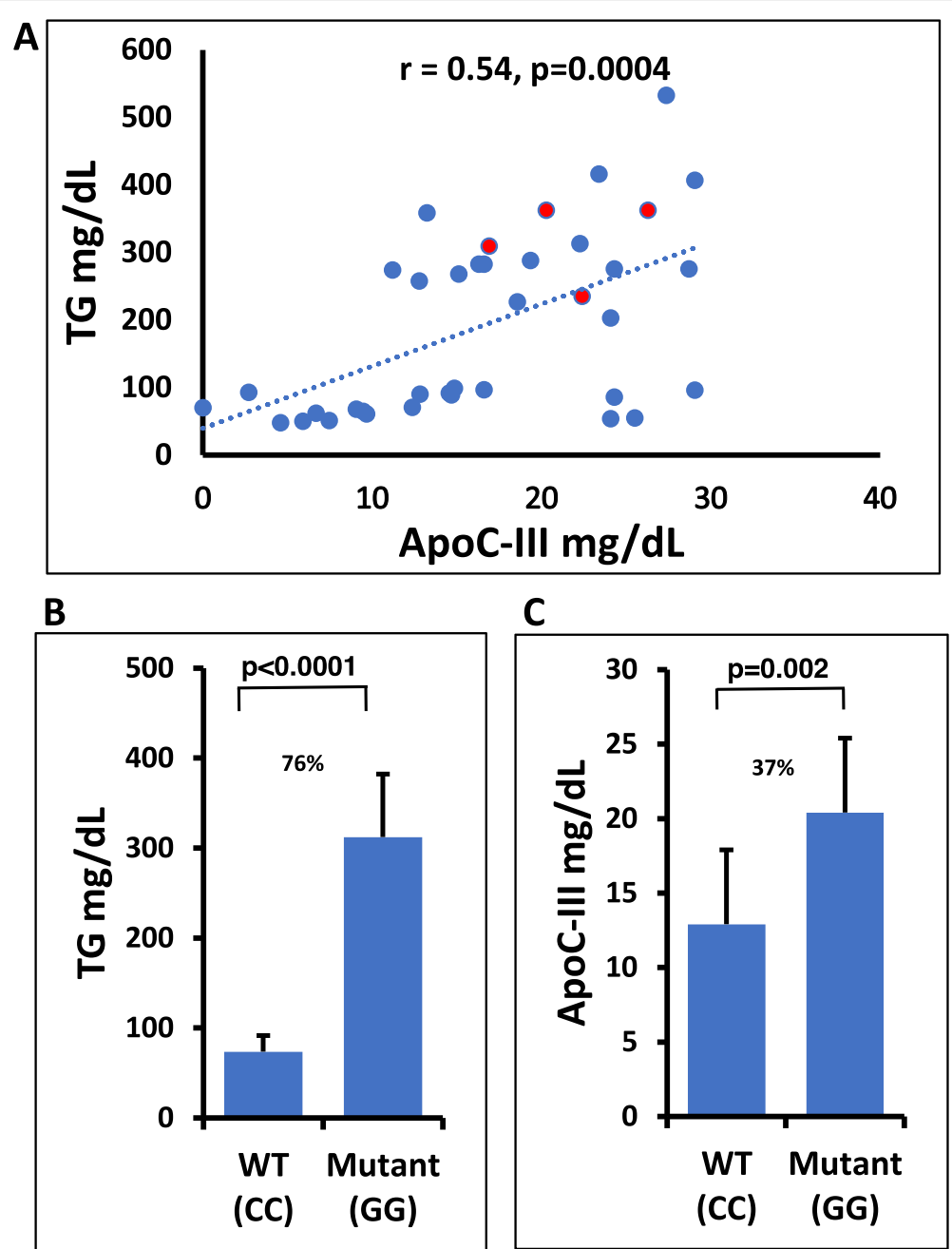

Fig. 4 Bar graphs show mean differences of (A) Scatter plot of ApoC-III concentration (mg/dL) X-axis vs TG levels (mg/dL) Y-axis in the homozygous mutant (GG) and wild-type (CC) genotype carriers of Sikh ancestry. Red dots indicate individuals with CAD (B) plasma TG mg/dL and (C) ApoC-III concentrations (mg/dL) among mutant (GG) and wild-type genotype carriers (CC) of rs5128 in Sikhs

Table 2 Allelic distribution of previously known APOC3 rare variants and their association with TG, HDL-C, and CAD

\begin{tabular}{|c|c|c|c|c|c|c|c|c|}
\hline Variant & Carrier & $\begin{array}{l}\text { Non- } \\
\text { Carrier }\end{array}$ & $\begin{array}{l}\% \\
\text { Carriers }\end{array}$ & $\begin{array}{l}\text { Mean TG } \\
\text { (mg/dL) } \\
\text { Carrier/Non- } \\
\text { carrier }\end{array}$ & $\begin{array}{l}\text { Mean HDL-C } \\
\text { (mg/dL) } \\
\text { Carrier/Non- } \\
\text { carrier }\end{array}$ & $\begin{array}{l}\text { CAD Among } \\
\text { Carriers }\end{array}$ & $\begin{array}{l}\text { CAD Among } \\
\text { Non-carriers }\end{array}$ & $\begin{array}{l}\text { Odds Ratio/Cl/P } \\
\text { (CAD) }\end{array}$ \\
\hline $\begin{array}{l}\text { rs373975305 } \\
\text { (IVS1-2G-A) }\end{array}$ & 16 & 390,916 & 0.004 & $\begin{array}{l}129.8 / 164.2 \\
(-21 \%)\end{array}$ & $46.5 / 45.4(2.4 \%)$ & $0 / 16$ & $20,145 / 370771$ & $\begin{array}{l}0.5695 \% \mathrm{Cl}(0.03-9.30) ; \\
p=0.684\end{array}$ \\
\hline $\begin{array}{l}\text { rs76353203 } \\
\text { (R19X) }\end{array}$ & 56 & 390,876 & 0.014 & $\begin{array}{l}84.5 / 163.4 \\
(-48.3 \%)\end{array}$ & $\begin{array}{l}60.5 / 45.7 \\
(32.4 \%)\end{array}$ & $5 / 51(8.9 \%)$ & $20,156 / 370720$ & $\begin{array}{l}1.8095 \% \mathrm{Cl}(0.72-4.52) ; \\
p=0.208\end{array}$ \\
\hline $\begin{array}{l}\text { rs138326449 } \\
\text { (IVS2 + 1G-A) }\end{array}$ & 1157 & 389,775 & 0.297 & $\begin{array}{l}98.9 / 157.9 \\
(-37.4 \%)\end{array}$ & $\begin{array}{l}61.4 / 47.1 \\
(30.4 \%)\end{array}$ & $39 / 1118$ (3.5\%) & $20,105 / 369670$ & $\begin{array}{l}0.6495 \% \mathrm{Cl}(0.47-0.88) \\
p=0.007\end{array}$ \\
\hline $\begin{array}{l}\text { rs } 147210663 \\
\text { (A43T) }\end{array}$ & 326 & 390,606 & 0.083 & $\begin{array}{l}122.5 / 163.4 \\
(-25 \%)\end{array}$ & $\begin{array}{l}50.4 / 45.7 \\
(10.3 \%)\end{array}$ & $11 / 315$ (3.5\%) & $20,131 / 370475$ & $\begin{array}{l}0.6495 \% \mathrm{Cl}(0.35-1.17) ; \\
p=0.150\end{array}$ \\
\hline $\begin{array}{l}\text { rs } 140621530 \\
\text { (IVS3 + 1G-T) }\end{array}$ & 24 & 390,908 & 0.006 & $\begin{array}{l}133.1 / 164.2 \\
(-18.9 \%)\end{array}$ & $\begin{array}{l}52.9 / 45.4 \\
(16.5 \%)\end{array}$ & $1 / 23(4 \%)$ & $30,010 / 360898$ & $\begin{array}{l}0.5295 \% \mathrm{Cl}(0.07-3.87) ; \\
p=0.526\end{array}$ \\
\hline
\end{tabular}

Variant data from Singapore Chinese (MEC_ Chinese) and Singapore Asian Indians (MEC_ Indian and SINDI) were not included because of the lack of information on CAD 


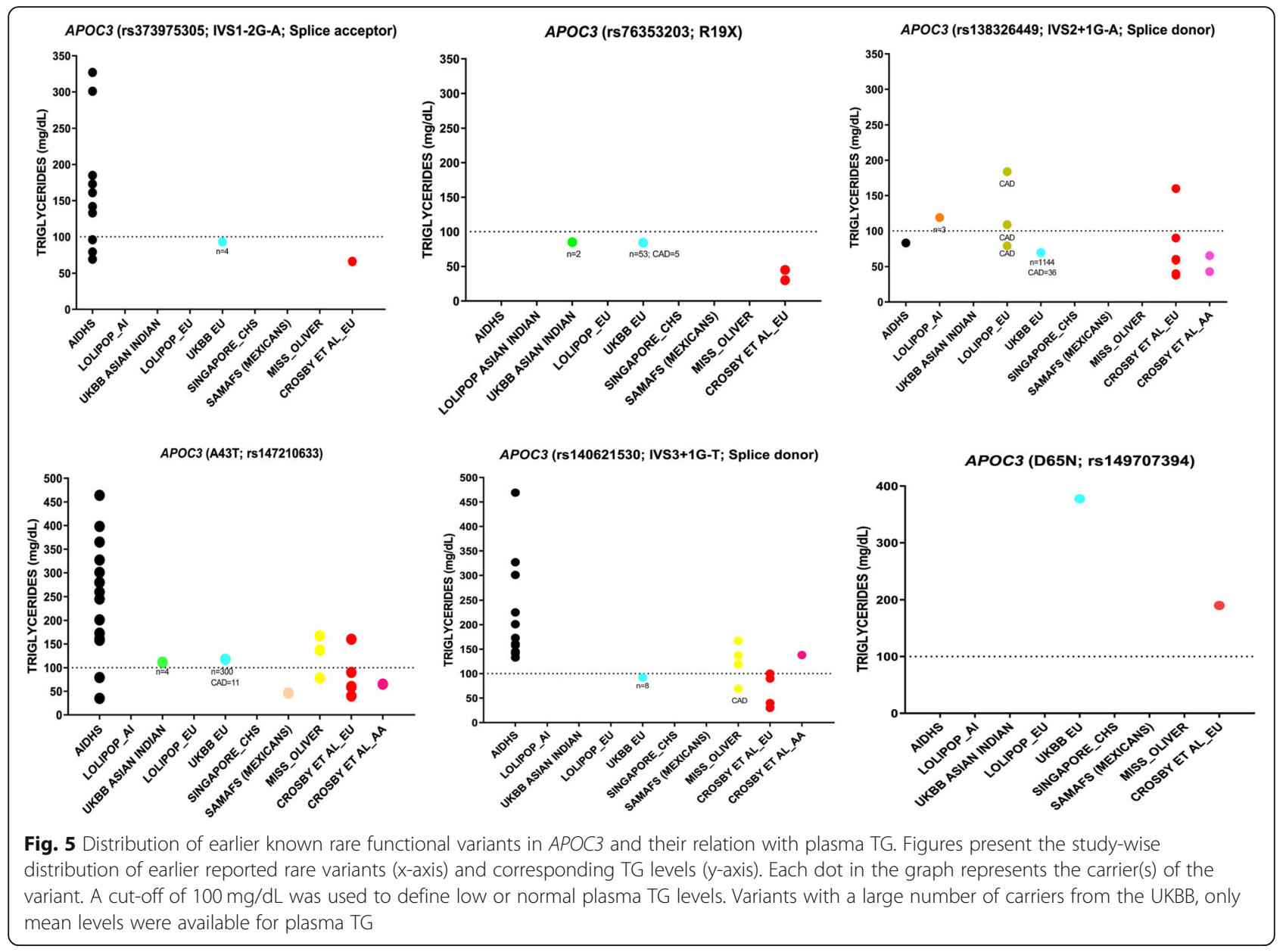

Europeans, whether the therapeutic inhibition of ApoC-III (based on the LoF variants) would be universally effective to prevent CAD in all dyslipidemic patients has not been explored. Moreover, in this study, we, for the first time, are reporting the role of $A P O C 3$ genetic variation on $\mathrm{TG}$ and $\mathrm{CAD}$ in Asian Indians, who are grossly underrepresented in genetic, clinical, biomarker research despite having a huge burden of cardiometabolic conditions. Also, because of the rapidly expanding role of genetic testing in disease prediction or diagnosis, the transferability of these findings in other diverse ethnic groups is imperative. Here, we are

Table 3 Allelic distribution of previously known APOC3 rare variants and their association with TG, HDL-C, and CAD only in Asian Indians

\begin{tabular}{|c|c|c|c|c|c|c|c|c|}
\hline Variant & Carrier & $\begin{array}{l}\text { Non- } \\
\text { Carrier }\end{array}$ & $\begin{array}{l}\% \\
\text { Carriers }\end{array}$ & $\begin{array}{l}\text { Mean TG } \\
\text { (mg/dL) } \\
\text { Carrier/ } \\
\text { Non-carrier }\end{array}$ & $\begin{array}{l}\text { Mean HDL mg/dL } \\
\text { Carrier/Non-carriers }\end{array}$ & $\begin{array}{l}\text { CAD Among } \\
\text { Carriers }\end{array}$ & $\begin{array}{l}\text { CAD Among } \\
\text { Non-carriers }\end{array}$ & $\begin{array}{l}\text { Odds Ratio/Cl/P } \\
\text { (CAD) }\end{array}$ \\
\hline $\begin{array}{l}\text { rs373975305 } \\
\text { (IVS1-2G-A) }\end{array}$ & 12 & 23,871 & 0.05 & $\begin{array}{l}166.6 / 173.6 \\
(-4 \%)\end{array}$ & $44 / 42.6(3.3 \%)$ & $0 / 12$ & $4364 / 19507$ & $\begin{array}{l}0.1895 \% \mathrm{Cl}(0.01- \\
3.02) ; p=0.233\end{array}$ \\
\hline $\begin{array}{l}\text { rs76353203 } \\
\text { (R19X) }\end{array}$ & 3 & 23,880 & 0.01 & $\begin{array}{l}84.9 / 171.5 \\
(-50.5 \%)\end{array}$ & $55.1 / 43.3(27.3 \%)$ & $0 / 3$ & $4364 / 19516$ & $\begin{array}{l}0.6495 \% \mathrm{Cl}(0.03- \\
12.37) ; p=0.767\end{array}$ \\
\hline $\begin{array}{l}\text { rs138326449 } \\
\text { (IVS2 + 1G-A) }\end{array}$ & 4 & 23,879 & 0.02 & $\begin{array}{l}101 / 165.8 \\
(-39.1 \%)\end{array}$ & $46.7 / 46.2(1.1 \%)$ & $0 / 4$ & $4351 / 19528$ & $\begin{array}{l}0.5095 \% \mathrm{Cl}(0.03- \\
9.26) ; p=0.641\end{array}$ \\
\hline $\begin{array}{l}\text { rs } 147210663 \\
\text { (A43T) }\end{array}$ & 22 & 23,861 & 0.09 & $\begin{array}{l}175.2 / 171.5 \\
(2.2 \%)\end{array}$ & $42.7 / 43.4(-1.6 \%)$ & $0 / 22$ & $4364 / 19497$ & $\begin{array}{l}0.0995 \% \mathrm{Cl}(0.01- \\
1.64) ; p=0.106\end{array}$ \\
\hline $\begin{array}{l}\text { rs } 140621530 \\
\text { (IVS3 + 1G-T) }\end{array}$ & 12 & 23,871 & 0.05 & $\begin{array}{l}221 / 173.6 \\
(27.3 \%)\end{array}$ & 43/42.6 (0.9\%) & $0 / 12$ & $4364 / 19507$ & $\begin{array}{l}0.1895 \% \mathrm{Cl}(0.01- \\
3.02) ; p=0.233\end{array}$ \\
\hline
\end{tabular}

Variant data from Singapore Asian Indians (MEC_ Indian and SINDI) were not included because of the lack of information on CAD 
reporting the role of $A P O C 3$ rare variants (known and novel) and common variants for their effects on TG, and CAD in Asian Indians, Mexicans, Chinese, and Europeans from India, Singapore, the UK, and the USA.

The MR analysis showed a TG raising common variant (rs5128) in the APOC3 gene may be involved in a modest increase in CAD risk by elevating circulating TG levels. A genetically instrumented per 1-SD increase in TG of $15 \mathrm{mg} / \mathrm{dL}$ would modestly increase CAD risk to $3 \% 95 \% \mathrm{CI}(0-5 \% ; p=0.042)$ (Fig. 3). Agreeing with earlier reports, this variant was not associated with LDLcholesterol in any of the participating cohorts in this study [39]. These results suggest that the observed association of $A P O C 3$ with CAD could be in the pathway independent of cholesterol metabolism. The two APOC3 SNPs, rs5128 and rs734104, were independently associated with increased TG concentrations. Notably, except for these two variants, no other SNP within the open reading frame of the $A P O C 3$ was associated with TG levels in any studied cohorts. The rs5128, also known as Sst-I, resides in the 3 '-untranslated region of the APOC3 gene and might enable microRNA binding and hence can change the transcriptional activity of ApoC-III, which ultimately would lead to higher plasma ApoC-III levels, increased TG, and the increased risk for CAD [40].

Further, we examined the role of earlier published LoF or reduced function splice/missense rare variants known to be protective against the CAD. One splice-donor variant IVS2 + 1G-A (rs138326449), which predominantly segregated in populations of European ancestry (with 99.6\% European heterozygous carriers), showed an $37 \%$ reduction in TG and had a significantly lower risk for CAD compared to wild type carriers $(0.6495 \% \mathrm{CI}$ $0.47-0.88 ; p=0.007$ ) (Table 2). However, the cardioprotective association of this variant could not be confirmed in Asian Indians in our study, despite with 39\% reduction in TG (Table 3). The reason might be the difference in MAF between Asian Indians $(\mathrm{MAF}=0.00013)$ and Europeans $(\mathrm{MAF}=0.002)$. Hence, a much larger sample would be required to confirm the cardioprotective role of this variant in other ethnic groups. With the exception of this splice variant, our data could not validate the cardioprotective role of other five rare functional variants (IVS1-2G-A (rs373975305); R19X (rs76353203); A43T (rs147210663); IVS3 + 1G-T (rs140621530); D65N (rs149707394); A10T (rs150821374). One of these six variants, A10T (rs150821374) was not found in any of our study cohorts. Generally, rare variants are population-specific and are often not seen in multiple ethnic populations $[23,41]$, but interestingly, these rare variants were present in Asian Indian Sikhs (Fig. 5). Nevertheless, their phenotypic effects were not replicated in these subjects as observed in earlier (predominantly European) studies [15, 18]. Our findings could not confirm the role of the most widely studied R19X (rs76353203) for its cardioprotective effect even in Europeans as first seen in Amish [15] and even in a Pakistani population [42]. Compared to the wild-type allele, 56 rare variant carriers of R19X (observed in the entire study) showed a $48.3 \%$ reduction in plasma TG (range $41.6-84.9 \mathrm{mg} / \mathrm{dL}$ ), and a large majority were Europeans from UKBB. These results agree with earlier published findings of Crawford et al., [43] where known rare LoF variants did not reveal any protection from CAD in the European Americans from BioVU biobank.

Previous studies examining the function of ApoC-III in animal and cell culture models have shown that the increased expression of ApoC-III attenuates the activity of LPL and reduces the clearance of TG-rich lipoproteins [5, 44]. The increase in ApoC-III concentration in hepatocytes stimulates the assembly of TG-rich VLDL and inhibits VLDL lipolysis [5]. Both the increased expression of ApoC-III and hypertriglyceridemia (HTG) are predictors of CAD risk in diabetic patients [45]. Thus, it is possible that due to the abnormalities in ApoC-III, the same rare LoF or splice variant may not show similar phenotypic effects in multiple carriers due to pleiotropic effects of other genes within the LD region. Perhaps, because of these differences, we and other studies are unable to confirm that carriers of the LoF variants have low TG.

On the other hand, our data on 396,644 individuals using a common variant as a genetic instrument suggest that the $A P O C 3$ elevates plasma TG levels through TGraising mutations. However, a modest increase in the CAD risk of $3 \%$ despite a substantial increase of $\sim 76 \%$ in TG levels by rs5128 suggests the possibility of pleiotropic effects of other variants or other nearby genes within the LD region of chromosome 11q23.

HTG is a multifactorial disease, and hence, the clinical management of these patients can be challenging. Adherence to lifestyle interventions such as weight loss, alcohol/tobacco withdrawal, use of lipid-lowering medications, and increased physical activity is emphasized as the essential principle for managing HTG in both the US and European guidelines [7]. Also, the development of novel technologies such as antisense oligonucleotides, siRNAs, dual apoC-II mimetic and apoC-III antagonist (called D6PV) offer promising results as potential therapies for HTG [6].

Substantial evidence in the literature on animal models and humans suggests that increased plasma ApoC-III levels increase with TG concentrations and are strong predictors of CAD [5, 44]. Although this study lacks measures on circulating levels of ApoC-III in all multi-ethnic datasets, plasma levels of ApoC-III in a small subset of Sikhs with wild type and mutant carriers of rs5128 revealed a $76 \%$ increase in TG levels and 37\% increase in ApoC-III 
levels among mutant homozygous carriers compared to the wild type carriers. Of note, some wild-type allele carriers with very low TG $(<80 \mathrm{mg} / \mathrm{dL})$ had high levels (>85th percentile) of ApoC-III (ranging between 24 and $29.5 \mathrm{mg} / \mathrm{dL}$ ). From these results, it appears that other variants within $A P O C 3$ could also be influencing the ApoCIII concentrations without affecting TG levels. Perhaps because of the missing information on ApoC-III levels, our MR results suggested only a modest increase in the risk for CAD. Availability of data with ApoC-III concentrations in the entire study subjects would be required to clarify the causal association of ApoC-III with CAD.

\section{Study strengths and limitations}

The role of the common variants (identified in this study) for increasing serum TG has been reported in several small studies. Here, we have not only consolidated the multi-ethnic datasets and validated the associations of these common variants with TG and CAD, but also, for the first time are reporting the causal association of genetically raised TG with the risk for CAD using the MR approach using data from 396,644 participants from 10 independent multi-ethnic cohorts. Further, as earlier published studies have primarily examined individuals from European populations, we have included data from Asian Indians from India and other South Asians (UKBB), and Europeans and other ethnic groups to analyze the role of genetic variation in APOC3 with CAD. For the first time, our study reports the role of earlier published rare variants for affecting TG and CAD in Asian Indians and other cohorts. Some limitations in this study deserve discussion. Firstly, even though our study included some independent cohorts of Asian Indians, the largest representation was still limited to the population of European origin. Thus, larger data sets of Asian Indians and other ethnic groups would be necessary to identify population-specific functional rare variants. In targeted sequencing of Punjabi Sikhs, we identified $\sim 200$ unique, rare variants; of these, 35 were associated with low TG levels (Supplementary Figure 1). However, their phenotypic effects could not be confirmed because of the small size of other Asian Indian cohorts and the lack of Sikh data. Secondly, the availability of ApoC-III concentrations in a large number of individuals would be required to clarify the causal association of ApoC-III with CAD. Thirdly, we evaluated the causal association with the CAD outcome using a single-sample MR and using the same datasets that could induce a bias if the genetic instrument is weak [46]. However, given our IV was strong and weighted on the TG effects, we do not expect that the data overlap had introduced any bias. Meta-analysis of 19 published studies, in fact, has reported a significant association between rs5128 and CAD in 11,186 subjects from multi- ethnic populations; however, because of the limited samples size of each study and heterogeneity, further validation was warranted [47]. Future independent evaluation using two-sample MR and using ApoC-III concentration in addition to TG would be helpful to confirm the causality. Fourthly, the data access was limited to summary statistics for many consortium cohorts that limited our ability to precisely correlate genotype-phenotype effects.

\section{Conclusions}

Overall, these results highlight the challenges of inclusion of rare variant information for clinical risk assessment and generalizability of implementation of ApoC-III inhibition for treating atherosclerotic disease in dyslipidemia. On the other hand, our MR study suggests that the genetically regulated hypertriglyceridemic effects of ApoC-III may be partially associated with the increased risk for $C A D$, and other variants within $A P O C 3$ and/or other nearby genes in the $11 \mathrm{q} 23$ cluster could be contributing to the increased ApoC-III levels and effecting CAD susceptibility. More studies on diverse populations would be needed to clarify the putative role of rare variants in $A P O C 3$ or nearby genes (within the cluster) for their effects on dyslipidemia and CAD.

\section{Clinical perspective}

Interindividual variation in circulating triglyceride (TG) is attributed to both genetic and environmental factors. Gene mapping studies have confirmed the strong influence of genetic factors for controlling circulating TG. However, the causal association of hypertriglyceridemia and the development of coronary artery disease (CAD) is unclear. Some loss-of-function rare variants in apolipoprotein-CIII (APOC3) have been suggested to decrease circulating TG and lower the risk for CAD. Yet, the results of relevant studies across diverse ethnic populations have been inconsistent and unclear. Populationbased clinical and observational studies often suffer from confounding due to reverse causation because it is difficult to account for individual variation related to obesity, cultural and ethnic/genetic variations in such studies.

On the other hand, human genetic information used by Mendelian randomization (MR) methods up to some extent can outwit the noise of the reverse causation using suitable gene variants as a genetic instrument and may help assess the underlying mechanistic association between the disease phenotype and biomarker. Our MR study suggests that the genetically regulated hypertriglyceridemia via $A P O C 3$ may be causally associated with the increased risk for CAD. From these findings, it appears that the siRNA/antisense inhibition of ApoC-III may be beneficial on the subsets of patients carrying these gain-of-function common variants (s). 


\section{Supplementary Information}

The online version contains supplementary material available at https://doi. org/10.1186/s12944-021-01531-8

Additional file 1: Supplementary Table 1. Diagnostic criteria for CAD cases and non-CAD controls in participating study cohorts. Supplementary Table 2. Work performed at each study site. Supplementary Table 3. Meta-analysis results of the association of APOC3 common variant rs5128 with plasma TG and the risk for CAD. Supplementary Figure 1. Detection of rare variants in APOC3 gene region by targeted sequencing in Sikhs from AIDHS/SDS (Discovery). Dots in the graph represent variant (SNV). Figures on the $x$-axis denote the number of variants (SNVs), and the $y$-axis represents the corresponding mean plasma TG $(\mathrm{mg} / \mathrm{dL})$, and a cut-off of $100 \mathrm{mg} / \mathrm{dL}$ was used to define low or normal plasma TG levels. Of a total 201 rare variants or SNVs (MAF<1\%) detected in Sikhs within APOC3 region (116697024-116711387), only 35 (17\%) had low TG (57-100 mg/dL) while a vast majority $166(83 \%)$ of these were linked to high or very high TG (101-865 mg/dL).

\section{Authors' contributions}

SG performed data analysis and helped in manuscript preparation; YT performed data analysis for UKBB, ZW performed data analysis for LOLIPOP; CJF and XS contributed in data analysis for Singapore studies; AM contributed in data analysis for SAMAFS; CJ, RJG, SC, VA, MP, ML contributed in recruitment, follow-up, and phenotyping for MISS-OLIVER; AB, MJ contributed in phenotyping and genotyping for AIDHS/SDS and MISS-OLIVER; ES is cohort Co-PI of MISS, CJE contributed in phenotyping and genotyping JP, DML, RD and JB are cohort PIs for SAMAFS; MAR is cohort PI of UKBB, GSW, SR, NKM, JRS contributed in recruitment and phenotyping for AIDHS/SDS; EST, VDRM, CYC, CS are cohort PIs for SINGAPORE cohorts; JC and JK are PIs of LOLIPOP; CEA advised in data analysis and helped in manuscript editing; DKS conceived, coordinated the consortium investigators, contributed to genotyping, and phenotyping as a cohort PI of AIDHS/SDS and MISS-OLIVER, and wrote the manuscript. The authors read and approved the final manuscript.

\section{Funding}

AIDHS/SDS: The Sikh Diabetes Study/ Asian Indian Diabetic Heart Study was supported by NIH grants-R01DK082766; R01DK118427 (NIDDK) and NOT-HG11-009 (NHGRI) and grants from Presbyterian Health Foundation and Harald Hamm Diabetes Center of Oklahoma. Sequencing services were provided through the RS\&G Service by the Northwest Genomics Center at the University of Washington, Department of Genome Sciences, under US Federal Government contract number HHSN268201100037C from the National Heart, Lung, and Blood Institute of the $\mathrm{NIH}$.

LOLIPOP: The LOLIPOP study is supported by the National Institute for Health Research (NIHR) Comprehensive Biomedical Research Centre Imperial College Healthcare NHS. Trust, the British Heart Foundation (S.P./04/002), the Medical Research Council (G0601966, G0700931), the Wellcome Trust (084723/Z/08/Z, 090532 \& 098381) the NIHR (RP-PG-0407-10371), the NIHR Official Development Assistance (ODA, award 16/136/68), the European Union FP7 (EpiMigrant, 279143) and H2020 programs (iHealth-T2D, 643774). We acknowledge the support of the MRC-PHE Centre for Environment and Health, and the NIHR Health Protection Research Unit on Health Impact of Environmental Hazards. The work was carried out in part at the NIHR/Wellcome Trust Imperial Clinical Research Facility. The views expressed are those of the author(s) and not necessarily those of the Imperial College Healthcare NHS. Trust, the NHS, the NIHR, or the Department of Health. We thank the participants and research staff who made the study possible. JC is supported by the Singapore Ministry of Health's National Medical Research Council under its Singapore Translational Research Investigator (STaR) Award (NMRC/ STaR/0028/2017).

SAMAFS: SAMAFS isis supported in part by National Institutes of Health (NIH) grants P01 HL045522, R01 DK047482, DK053889, R01 HL113323, R37 MH059490, and T2D-GENES Consortium grants (U01 DK085524, U01 DK085584, U01 DK085501, U01 DK085526, and U01 DK085545). We thank the participants of the San Antonio Family Heart Study and the San Antonio Family Diabetes/Gallbladder Study for their continued cooperation and participation in our research programs.

MISS-OLIVER: The OLIVER and MISS are partly supported by NIH grants -R01DK082766 funded by the National Institute of Health (NIDDK),
Presbyterian Health Foundation Grants, the College of Medicine Alumni Association grant, and Leinbach Seed Grant from the University of Oklahoma Health Sciences Center. The authors thank all the participants of MISS-OLIVER participants and are grateful for their contribution to this study. UKBB: YT is supported by a Funai Overseas Scholarship from the Funai Foundation for Information Technology and the Stanford University School of Medicine. MAR is partially supported by Stanford University and a National Institute of Health center for Multi-and Trans-ethnic Mapping of Mendelian and Complex Diseases grant (5 U01 HG009080) and partially supported by the National Human Genome Research Institute (NHGRI) of the National Institutes of Health (NIH) under award R01HG010140.

\section{Availability of data and materials}

The datasets used and/or analyzed during the current study are available from the corresponding author on reasonable request.

\section{Declarations}

Ethics approval and consent to participate

All AIDHS/SDS protocols and consent documents were reviewed and approved by the University of Oklahoma Health Science Center's Institutional Review Board (IRB) as well as the Human Subject Protection (Ethics) committees at the participating hospitals and institutes in India. The LOLIPOP study is approved by the National Research Ethics Service (07/ H0712/150) and all participants gave written informed consent at enrollment. The SAFHS and SAFDGS study-specific protocols have been approved by the Institutional Review Boards of the University of Texas Health San Antonio and the University of Texas Rio Grande Valley, and informed consent was obtained from all SAFHS and SAFDGS participants, respectively. Ethics approval for the UKBB was obtained from the North West Centre for Research Ethics Committee (11/NW/0382). All the participants of UKBB provided written informed consent.

\section{Consent for publication}

NA.

\section{Competing interests}

We declare that no conflict of interest could be perceived as prejudicing the impartiality of the research reported.

\section{Author details}

${ }^{1}$ Department of Pediatrics, College of Medicine, University of Oklahoma Health Sciences Center, 940 Stanton L. Young Blvd., Rm 317 BMSB, Oklahoma City, OK 73104, USA. ²Department of Biomedical Data Science, School of Medicine, Stanford University, Stanford, California, USA. ${ }^{3}$ Department of Epidemiology and Biostatistics, Imperial College London, London W2 1PG, UK. ${ }^{4}$ Department of Cardiology, Ealing Hospital, Middlesex UB1 3HW, UK. ${ }^{5}$ Saw Swee Hock School of Public Health, National University of Singapore and National University Health System, Singapore 117549, Singapore. ${ }^{6}$ Department of Human Genetics and South Texas Diabetes and Obesity Institute, University of Texas Rio Grande Valley, Brownsville, TX, USA. ${ }^{7}$ Department of Surgery, Oklahoma University of Health Sciences Center, Oklahoma City, OK, USA. ${ }^{8}$ Department of Neurology, University of Oklahoma Health Sciences Center, 920 S. L Young Blvd \#2040, Oklahoma City, OK 73104, USA. 'Departments of Medicine and Epidemiology and Biostatistics, University of Texas Health San Antonio, San Antonio, TX, USA. ${ }^{10}$ Hero DMC Heart Institute, Ludhiana, Punjab, India. ${ }^{11}$ Central University of Punjab, Bathinda, Punjab, India. ${ }^{12}$ All India Institute of Medical Sciences and Research, New Delhi, India. ${ }^{13}$ Department of Pediatrics, Section of Endocrinology, Oklahoma University of Health Sciences Center, Oklahoma City, OK, USA. ${ }^{14}$ Department of Medicine, Yong Loo Lin School of Medicine, National University Health System, Singapore 119228 , Singapore. ${ }^{15}$ Department of Nutrition, Harvard T.H. Chan School of Public Health, Boston, MA, USA. ${ }^{16}$ Duke-NUS Medical School, Singapore 169857, Singapore. ${ }^{17}$ Singapore Eye Research Institute, Singapore National Eye Centre, Singapore 168751,

Singapore. ${ }^{18}$ National University of Singapore, Singapore 119077, Singapore.

${ }^{19}$ Lee Kong Chan School of Medicine, Nanyang Technological University, Singapore 308232, Singapore. ${ }^{20}$ Imperial College Healthcare NHS Trust, Imperial College London, London W12 OHS, UK. ${ }^{21}$ MRC-PHE Centre for Environment and Health, Imperial College London, London W2 1PG, UK. ${ }^{22}$ National Heart and Lung Institute, Imperial College London, London W12 
ONN, UK. ${ }^{23}$ Department of Pharmaceutical Sciences, University of Oklahoma Health Sciences Center, Oklahoma City, OK, USA. ${ }^{24}$ Department of Physiology, College of Medicine, University of Oklahoma Health Sciences Center, Oklahoma City, OK, USA. ${ }^{25}$ Oklahoma Center for Neuroscience, University of Oklahoma Health Sciences Center, Oklahoma City, OK, USA. ${ }^{26}$ Harold Hamm Diabetes Center, University of Oklahoma Health Sciences Center, Oklahoma City, OK, USA.

Received: 29 July 2021 Accepted: 25 August 2021

Published online: 21 September 2021

\section{References}

1. Surendran RP, Visser ME, Heemelaar S, Wang J, Peter J, Defesche JC, et al. Mutations in LPL, APOC2, APOA5, GPIHBP1 and LMF1 in patients with severe hypertriglyceridaemia. J Intern Med. 2012;272(2):185-96.

2. Santos-Baez LS, Ginsberg HN. Hypertriglyceridemia-causes, significance, and approaches to therapy. Front Endocrinol. 2020;11:616.

3. Mantel-Teeuwisse AK, Kloosterman JM. Maitland-van der zee AH, Kungel OH, Porsius Av, de Boer a. drug-induced lipid changes: a review of the unintended effects of some commonly used drugs on serum lipid levels. Drug Saf. 2001;24(6):443-56.

4. Wolska A, Dunbar RL, Freeman LA, Ueda M, Amar MJ, Sviridov DO, et al. Apolipoprotein C-II: new findings related to genetics, biochemistry, and role in triglyceride metabolism. Atherosclerosis. 2017;267:49-60.

5. Sacks FM, Alaupovic P, Moye LA, Cole TG, Sussex B, Stampfer MJ, et al. VLDL, apolipoproteins $B, C I I I$, and $E$, and risk of recurrent coronary events in the cholesterol and recurrent events (CARE) trial. Circulation. 2000;102(16):1886-92.

6. Wolska A, Yang ZH, Remaley AT. Hypertriglyceridemia: new approaches in management and treatment. Curr Opin Lipidol. 2020;31(6):331-9.

7. Grundy SM, Stone NJ, Bailey AL, Beam C, Birtcher KK, Blumenthal RS, et al. 2018 AHA/ACC/AACVPR/AAPA/ABC/ACPM/ADA/AGS/APhA/ASPC/NLA/ PCNA guideline on the Management of Blood Cholesterol: a report of the American College of Cardiology/American Heart Association task force on clinical practice guidelines. J Am Coll Cardiol. 2019;73(24):e285-350.

8. Mach F, Baigent C, Catapano AL, Koskinas KC, Casula M, Badimon L, et al. 2019 ESC/EAS guidelines for the management of dyslipidaemias: lipid modification to reduce cardiovascular risk. Eur Heart J. 2020;41(1):111-88.

9. Koren E, Corder C, Mueller G, Centurion H, Hallum G, Fesmire J, et al. Triglyceride enriched lipoprotein particles correlate with the severity of coronary artery disease. Atherosclerosis. 1996;122(1):105-15.

10. Cohn JS, Patterson BW, Uffelman KD, Davignon J, Steiner G. Rate of production of plasma and very-low-density lipoprotein (VLDL) apolipoprotein C-III is strongly related to the concentration and level of production of VLDL triglyceride in male subjects with different body weights and levels of insulin sensitivity. J Clin Endocrinol Metab. 2004;89(8):3949-55.

11. Miller M, Rhyne J, Chen H, Beach V, Ericson R, Luthra K, et al. APOC3 promoter polymorphisms C-482T and T-455C are associated with the metabolic syndrome. Arch Med Res. 2007;38(4):444-51.

12. Pollex RL, Ban MR, Young TK, Bjerregaard P, Anand SS, Yusuf S, et al. Association between the $-455 \mathrm{~T}>\mathrm{C}$ promoter polymorphism of the APOC3 gene and the metabolic syndrome in a multi-ethnic sample. BMC Med Genet. 2007;8:80.

13. Teslovich TM, Musunuru K, Smith AV, Edmondson AC, Stylianou IM, Koseki $\mathrm{M}$, et al. Biological, clinical and population relevance of 95 loci for blood lipids. Nature. 2010;466(7307):707-13.

14. Braun TR, Been LF, Singhal A, Worsham J, Ralhan S, Wander GS, et al. A replication study of GWAS-derived lipid genes in Asian Indians: The Chromosomal Region 11q23.3 Harbors Loci Contributing to Triglycerides. PLoS One. 2012;7(5):e37056.

15. Pollin TI, Damcott CM, Shen H, Ott SH, Shelton J, Horenstein RB, et al. A null mutation in human APOC3 confers a favorable plasma lipid profile and apparent cardioprotection. Science. 2008:322(5908):1702-5.

16. Tg, Hdl Working Group of the Exome Sequencing Project NHL, Blood I, Crosby J, Peloso GM, Auer PL, et al. Loss-of-function mutations in APOC3, triglycerides, and coronary disease. N Engl J Med. 2014;371(1):22-31.

17. Liu H, Labeur C, Xu CF, Ferrell R, Lins L, Brasseur R, et al. Characterization of the lipid-binding properties and lipoprotein lipase inhibition of a novel apolipoprotein C-III variant Ala23Thr. J Lipid Res. 2000;41(11):1760-71.

18. Jorgensen AB, Frikke-Schmidt R, Nordestgaard BG, Tybjaerg-Hansen A. Lossof-function mutations in APOC3 and risk of ischemic vascular disease. N Engl J Med. 2014;371(1):32-41.
19. Palaniappan LP, Araneta MR, Assimes TL, Barrett-Connor EL, Carnethon MR, Criqui $\mathrm{MH}$, et al. Call to action: cardiovascular disease in Asian Americans: a science advisory from the American Heart Association. Circulation. 2010;122(12):1242-52.

20. Forouhi NG, Sattar N, Tillin T, McKeigue PM, Chaturvedi N. Do known risk factors explain the higher coronary heart disease mortality in south Asian compared with European men? Prospective follow-up of the Southall and Brent studies, UK. Diabetologia. 2006;49(11):2580-8.

21. Saxena R, Saleheen D, Been LF, Garavito ML, Braun T, Bjonnes A, et al. Genome-wide association study identifies a novel locus contributing to type 2 diabetes susceptibility in Sikhs of Punjabi origin from India. Diabetes. 2013;62(5):1746-55.

22. Saxena R, Bjonnes A, Prescott J, Dib P, Natt P, Lane J, et al. Genome-wide association study identifies variants in casein kinase II (CSNK2A2) to be associated with leukocyte telomere length in a Punjabi Sikh diabetic cohort. Circ Cardiovasc Genet. 2014;7(3):287-95.

23. Sapkota BR, Hopkins R, Bjonnes A, Ralhan S, Wander GS, Mehra NK, et al. Genome-wide association study of $25(\mathrm{OH})$ vitamin D concentrations in Punjabi Sikhs: results of the Asian Indian diabetic heart study. J Steroid Biochem Mol Biol. 2016;158:149-56.

24. Kooner JS, Saleheen D, Sim X, Sehmi J, Zhang WH, Frossard P, et al. Genomewide association study in individuals of south Asian ancestry identifies six new type 2 diabetes susceptibility loci. Nat Genet. 2011;43(10):984-U94.

25. Sim X, Ong RT, Suo C, Tay WT, Liu J, Ng DP, et al. Transferability of type 2 diabetes implicated loci in multi-ethnic cohorts from Southeast Asia. PLoS Genet. 2011;7(4):e1001363.

26. DeBoever C, Tanigawa Y, Aguirre M, Mclnnes G, Lavertu A, Rivas MA. Assessing digital Phenotyping to enhance genetic studies of human diseases. Am J Hum Genet. 2020;106(5):611-22.

27. Nang EE, Gitau Ngunjiri SA, Wu Y, Salim A, Tai ES, Lee J, et al. Validity of the international physical activity questionnaire and the Singapore prospective study program physical activity questionnaire in a multiethnic urban asian population. BMC Med Res Methodol. 2011;11:141.

28. Bycroft C, Freeman C, Petkova D, Band G, Elliott LT, Sharp K, et al. The UK biobank resource with deep phenotyping and genomic data. Nature. 2018:562(7726):203-9.

29. Mitchell BD, Kammerer CM, Blangero J, Mahaney MC, Rainwater DL, Dyke B, et al. Genetic and environmental contributions to cardiovascular risk factors in Mexican Americans. The San Antonio family heart study. Circulation. 1996;94(9):2159-70.

30. Sidorov E, Bejar C, Xu C, Ray B, Reddivari L, Chainakul J, et al. Potential metabolite biomarkers for acute versus chronic stage of ischemic stroke: a pilot study. J Stroke Cerebrovasc Dis. 2020;29(4):104618.

31. Das S, Forer L, Schonherr S, Sidore C, Locke AE, Kwong A, et al. Nextgeneration genotype imputation service and methods. Nat Genet. 2016; 48(10):1284-7.

32. Willer CJ, Li Y, Abecasis GR. METAL: fast and efficient meta-analysis of genomewide association scans. Bioinformatics. 2010;26(17):2190-1.

33. Pruim RJ, Welch RP, Sanna S, Teslovich TM, Chines PS, Gliedt TP, et al. LocusZoom: regional visualization of genome-wide association scan results. Bioinformatics. 2010;26(18):2336-7.

34. K PMaG. Principles of biostatistics CENGAGE learning (3/9/2000); 2000 .

35. Smith GD, Ebrahim S. 'Mendelian randomization': can genetic epidemiology contribute to understanding environmental determinants of disease? Int J Epidemiol. 2003;32(1):1-22.

36. Sekula P, Del Greco MF, Pattaro C, Kottgen A. Mendelian randomization as an approach to assess causality using observational data. J Am Soc Nephrol. 2016;27(11):3253-65.

37. Qamar A, Khetarpal SA, Khera AV, Qasim A, Rader DJ, Reilly MP. Plasma apolipoprotein C-III levels, triglycerides, and coronary artery calcification in type 2 diabetics. Arterioscler Thromb Vasc Biol. 2015;35(8):1880-8.

38. Gaudet D, Alexander VJ, Baker BF, Brisson D, Tremblay K, Singleton W, et al. Antisense inhibition of Apolipoprotein C-III in patients with hypertriglyceridemia. N Engl J Med. 2015;373(5):438-47.

39. Silbernagel G, Scharnagl H, Kleber ME, Hoffmann MM, Delgado G, Stojakovic T, et al. Common APOC3 variants are associated with circulating ApoC-III and VLDL cholesterol but not with total apolipoprotein B and coronary artery disease. Atherosclerosis. 2020;311:84-90.

40. Yao Z, Wang Y. Apolipoprotein C-III and hepatic triglyceride-rich lipoprotein production. Curr Opin Lipidol. 2012;23(3):206-12.

41. Cooper RS, Tayo B, Zhu X. Genome-wide association studies: implications for multiethnic samples. Hum Mol Genet. 2008:17(R2):R151-5.

42. Saleheen D, Natarajan P, Armean IM, Zhao W, Rasheed A, Khetarpal SA, et al. Human knockouts and phenotypic analysis in a cohort with a high rate of consanguinity. Nature. 2017;544(7649):235-9. 
43. Crawford DC, Restrepo NA, Diggins KE, Farber-Eger E, Wells QS. Frequency and phenotype consequence of APOC3 rare variants in patients with very low triglyceride levels. BMC Med Genet. 2018;11(Suppl 3):66.

44. Lee SJ, Campos H, Moye LA, Sacks FM. LDL containing Apolipoprotein CIII is an independent risk factor for coronary events in diabetic patients. Arterioscler Thromb Vasc Biol. 2003;23(5):853-8.

45. Lee SJ, Moye LA, Campos H, Williams GH, Sacks FM. Hypertriglyceridemia but not diabetes status is associated with VLDL containing apolipoprotein CIII in patients with coronary heart disease. Atherosclerosis. 2003;167(2):293-302.

46. Burgess S, Davies NM, Thompson SG. Bias due to participant overlap in twosample Mendelian randomization. Genet Epidemiol. 2016;40(7):597-608.

47. Li Y, Li C, Gao J. Apolipoprotein C3 gene variants and the risk of coronary heart disease: a meta-analysis. Meta Gene. 2016;9:104-9.

\section{Publisher's Note}

Springer Nature remains neutral with regard to jurisdictional claims in published maps and institutional affiliations.

Ready to submit your research? Choose BMC and benefit from:

- fast, convenient online submission

- thorough peer review by experienced researchers in your field

- rapid publication on acceptance

- support for research data, including large and complex data types

- gold Open Access which fosters wider collaboration and increased citations

- maximum visibility for your research: over $100 \mathrm{M}$ website views per year

At BMC, research is always in progress.

Learn more biomedcentral.com/submissions 